\title{
PENGARUH KEBAHAGIAAN DAN BUDAYA ORGANISASI TERHADAP PELAYANAN PERAWAT DI RUMAH SAKIT UMUM DAERAH AJI MUHAMMAD PARIKESIT TENGGARONG
}

\author{
THE EFFECT OF HUMANITY AND ORGANIZATIONAL CULTURE ON NURSE SERVICES \\ IN GENERAL HOSPITAL REGIONS AJI MUHAMMAD PARIKESIT TENGGARONG
}

\author{
Ervina Ismirawati \\ Fakultas Psikologi, Universitas 17 Agustus 1945 Samarinda \\ Email: ervinaismirawati@gmail.com
}

\begin{abstract}
Abstrak: Penelitian ini bertujuan untuk mengetahui apakah ada pengaruh kebahagiaan dan budaya organisasi terhadap pelayanan perawat di RSUD Aji Muhammad Parikesit Tenggarong. Sehingga terdapat 3 pengaruh yang akan diselidiki dalam penelitian ini, yaitu : Kebahagiaan dan dan budaya organisasi terhadap pelayanan perawat di RSUD Aji Muhammad Parikesit Tenggarong. Penelitian dikenakan kepada perawat di RSUD Aji Muhammad Parikesit Tenggarong. Subjek dalam penelitian ini adalah 80 perawat di RSUD Aji Muhammad Parikesit Tenggarong yang merawat pasien di rawat inap. Pengambilan sampel pada penelitian ini menggunakan teknik probabilitas sampling dimana setiap populasi memberikan peluang yang sama bagi setiap unsur untuk dipilih menjadi anggota sampel. Teknik analisis data yang digunakan adalah analisis regresi linier berganda. Hasil penelitian menunjukkan terdapat pengaruh positif dan signifikan antara kebahagiaan dan budaya organisasi terhadap pelayanan perawat di RSUD Aji Muhammad Parikesit Tenggarong dengan nilai probabilitas $\mathrm{p}=0,000(\mathrm{p}<0,05)$ maka terdapat pengaruh kebahagiaan (X1) dan budaya organisasi (X2) terhadap pelayanan perawat (Y) dengan nilai R Square 0,426. Artinya ada sumbangan efektif kebahagiaan dan budaya organisasi sebesar $42,6 \%$ terhadap pelayanan perawat. Jadi dapat disimpulkan semakin tinggi kebahagiaan dan budaya organisasi maka pelayanan perawat akan semakin baik.
\end{abstract}

Kata Kunci: Kebahagiaan, Budaya Organisasi, Pelayanan Perawat

\begin{abstract}
This study aims to determine whether there is happiness and influence of organizational culture on nursing care in hospitals Aji Muhammad Parikshit Tenggarong. So there are three influences that will be investigated in this study, namely: Happiness and culture of the organization and the service of nurses in hospitals Aji Muhammad Parikshit Tenggarong. Research subjected to nurses in hospitals Aji Muhammad Parikshit Tenggarong. Subjects in this study were 80 nurses in hospitals Aji Muhammad Parikesit Tenggarong caring for the patient in hospitalization. Sampling in this study uses probability sampling technique in which each population give equal opportunity for each element to be elected as members of the sample. Data analysis technique used is multiple linear regression analysis. The results showed a positive and significant influence between happiness and organizational culture on nursing care in hospitals Aji Muhammad Parikshit Tenggarong with a probability value of $p=0.000(p<0.05)$, then there is the effect of happiness (X1) and organizational culture (X2) to services nurse $(Y)$ with a value of $R$ Square of 0.426. That is no effective contribution happiness and organizational culture of $42.6 \%$ of the nursing service. So it can be concluded the higher happiness and culture of the organization, the better nursing services.
\end{abstract}

Keywords: Kutai Tribe, PNS and Non PNS, Subjective Well-Being. 


\section{PENDAHULUAN}

Dalam era globalisasi dan modernisasi dunia saat ini, kemajuan di segala bidang, termasuk kesehatan dituntut agar lebih berkualitas. Rumah sakit juga berubah dalam menjalankan pelayanan kesehatan kepada pasien, di mana saat ini tidak lagi memfokuskan karya amal saja, tetapi juga meningkatkan pelayanan kesehatan yang baik.

Pada tahun 2008 saja berdasarkan Data International Medical Travel Journal, Malaysia dan Singapura adalah negara yang paling sering dikunjungi orang Indonesia untuk berobat. Jumlah penduduk Indonesia yang berobat ke Singapura Tahun 2007 sebanyak 226.200 orang, sedangkan yang berobat ke Malaysia berjumlah 70.414 (Tahun 2006), 221.538 (Tahun 2007), dan 288.000 (Tahun 2008). Jika melihat data ini, maka ada sekitar 500.000 orang Indonesia yang berobat ke luar negeri.

Apalagi pada jaman sekarang menurut data Kementrian Pariwisata dan Ekonomi Kreatif pada tahun 2012 terdapat 600.000 orang Indonesia berobat ke luar negeri dengan devisa negara yang mengalir ke negara-negara tetangga sebesar 13,5 triliun.

Hal ini bisa terjadi dikarenakan mulai dari anggaran kesehatan nasional yang masih dibawah $5 \%$, tidak sesuai dengan amanat undang-undang, sampai kepada aturan atau kepastian hukum yang „kurang jelas". Selain itu sejak tahun 2015, dunia kesehatan Indonesia akan menghadapi era ASEAN Economic Community (masyarakat ekonomi ASEAN). Ketika sistem ini berlaku, akan terbentuk semacam ,perdagangan bebas" dimana akan terjadi persaingan secara terbuka lapangan kerja khususnya tenaga medis di negara-negara ASEAN. Sehingga bila Indonesia tidak ingin kalah bersaing di negeri sendiri, mulai dari sekarang kompetensi serta profesionalitas tenaga medis ditingkatkan.

dalam topik ini dokter harus lah

Menurut Kotler (1997), kepuasan konsumen adalah perasaan senang atau kecewa seseorang yang berasal dari perbandingan antara kesannya terhadap kinerja atau hasil suatu produk dengan 4 harapan harapannya. Bila kinerja produk tidak sesuai dengan harapannya setelah dikonsumsi maka konsumen akan merasa tidak puas sehingga dari pembelajaran tersebut dia akan merasa kecewa. Namun bila terjadi sebaliknya yaitu kinerja produk atau jasa sesuai dengan harapannya, maka konsumen akan merasa amat bergairah untuk mengkonsumsi produk atau jasa itu kembali (Steffi Mongkaren, 2013).

Seorang perawat dalam pekerjaannya selalu bertemu dengan beraneka ragam kepribadian orang yang semuanya mempunyai ciri khas masing-masing. Seorang perawat selain harus mengenal perbedaan di antara pasien, teman sejawat, supervisor, instruktur, teman dan keluarganya, juga harus mengetahui dirinya sendiri juga memiliki perbedaan dan menyadari bahwa ciri-ciri khas tertentu dapat memudahkan usaha untuk mencapai interaksi positif dengan orang lain.

Selanjutnya, perawat perlu mendalami beberapa sifat yang sedapat mungkin dimiliki oleh seorang perawat dalam hubungannya dengan pekerjaannya dan hubungan sosial. Melalui aksi timbale balik dan interaksi antara perawat dengan orang lain, salah satunya adalah keriangan yang merupakan bentuk dari ungkapan kebahagiaan dengan wajah yang terus menerus tertawa atau tersenyum sepanjang hari untuk menunjukan sikap riang, perawat tidak perlu tertawa dan tersenyum terus menerus. Sikap riang dapat diperhatikan dengan sikap biasa, tanpa keluhan, tanpa menggerutu, tanpa marah atau cacian. Memang mudah memperlihatkan sikap riang apabila keadaan sekitar menyenangkan. Seorang perawat sebaiknya dapat menghadapi situasi yang penuh kesulitan dan kekecewaan kepada orang lain. Sedapat mungkin seorang perawat siap tersenyum, memberi salam dengan ramah, dan memiliki sikap umum yang optimis dan percaya serta memberikan energi positive bagi pasien (Gunarsa, 2012). 


\section{METODE PENELITIAN}

Berdasarkan judul yang dikemukakan, maka jenis penelitian yang digunakan adalah penelitiaan kuantitatif korelasional, yaitu metode penelitian yang berlandaskan pada filsafat positivisme, digunakan untuk meneliti pada populasi atau sampel tertentu, teknik pengambilan sampel pada umumnya dilakukan secara random, pengumpulan data menggunakan instrumen penelitian, analisis data bersifat kuantitatif/statistik dengan tujuan untuk menguji hipotesis yang telah ditetapkan (Sugiono, 2011).

\section{SUBJEK}

Populasi yang ada di RSUD A.M Parikest 115 orang perawat di ruang rawat inap.

Sampel adalah bagian dari jumlah dan karakteristik yang dimiliki oleh polulasi tersebut (Sugiono, 2011). Teknik pengambilan sampel menggunakan teknik probability sampling yaitu teknik pengambilan sampel yang memberikan peluang yang sama bagi setiap unsur populasi untuk dipilih menjadi anggota sampel (Sugiono, 2011). Sampel yang akan digunakan dalam penelitian ini 80 orang perawat (Sugiono, 2011).

Adapun kriteria yang menjadi responden dalam penelitian ini adalah :

Perawat di Instalasi Rawat Inap atau perawat yang melayanai dan memberikan pelayanan khusus bagi pasien yang harus dirawat di rumah sakit.

\section{ALAT UKUR}

Berdasarkan hasil uji validitas skala pelayanan perawat yang terdiri dari 60 item yang diberikan pada subjek 30 orang subjek penelitian menunjukkan 37 aitem memenuhi daya diskriminasi aitem. Aitem - aitem tersebut memiliki koefesien korelasi aitem dengan skor corrected item-total correlation (nilai $\mathrm{r}$ hitung) bekisar antara 0,318 - 0,867. Sedangkan aitem gugur berjumlah 23 aitem. 6

Hasil uji reliabilitas pada skala kebahagiaan diperoleh koefesien reliabilitas 0,827 . Hasil ini menunjukkan bahwa koefesien reliabilitas skala kebahagiaan telah melebihi batas minimal koefesien reliabilitas 0,70. Koefesien reliabilitas skala kebahagiaan sebesar 0,827 mimiliki arti perbedaan variasi yang tampak pada skor. Skala kebahagiaan mampu mencerminkan $82,7 \%$ dari variasi skor murni kelompok subjek yang bersangkutan dan sisanya $17,3 \%$ skor yang tampak disebabkan pada skala pengukuran.

Berdasarkan hasil uji validitas skala kebahagiaan yang terdiri dari 60 item yang diberikan pada subjek 30 orang subjek penelitian menunjukkan 25 aitem memenuhi daya diskriminasi aitem. Aitem - aitem tersebut memiliki koefesien korelasi aitem dengan skor corrected item-total correlation (nilai $\mathrm{r}$ hitung) bekisar antara 0,310-0,698. Sedangkan aitem gugur berjumlah 35 aitem.

Hasil uji reliabilitas pada skala kebahagiaan diperoleh koefesien reliabilitas 0,819 . Hasil ini menunjukkan bahwa koefesien reliabilitas skala kebahagiaan telah melebihi batas minimal koefesien reliabilitas 0,70. Koefesien reliabilitas skala kebahagiaan sebesar 0,819 mimiliki arti perbedaan variasi yang tampak pada skor. Skala kebahagiaan mampu mencerminkan $81,9 \%$ dari variasi skor murni kelompok subjek yang bersangkutan dan sisanya $18,1 \%$ skor yang tampak disebabkan pada skala pengukuran.

Berdasarkan hasil uji validitas skala budaya organisasi yang terdiri dari 60 item yang diberikan pada subjek 30 orang subjek penelitian menunjukkan 27 aitem memenuhi daya diskriminasi aitem. Aitem - aitem tersebut memiliki koefesien korelasi aitem dengan skor corrected item-total correlation (nilai $\mathrm{r}$ hitung) bekisar antara 0,304 - 0,780. Sedangkan aitem gugur berjumlah 33 aitem.

Hasil uji reliabilitas pada skala budaya organisasi diperoleh koefesien reliabilitas 0,832 . Hasil ini menunjukkan bahwa koefesien reliabilitas skala pelayanan perawat telah melebihi batas minimal koefesien reliabilitas 0,70 . Koefesien reliabilitas skala budaya organisasi sebesar 0,832 mimiliki arti perbedaan variasi yang 7

tampak pada skor. Skala pelayanan perawat mampu mencerminkan $83,2 \%$ dari 
variasi skor murni kelompok subjek yang bersangkutan dan sisanya $16,8 \%$ skor yang tampak disebabkan pada skala pengukuran.

\section{HASIL DAN PEMBAHASAN}

\section{Uji Normalitas}

Uji normalitas digunakan untuk mengetahui apakah populasi data terdistribusi atau tidak. Data yang diuji adalah sebaran data pada instrument kebahagiaan (X1) budaya organisasi (X2) dan pelayanan perawat (Y). Pengujian normalitas dalam penelitian ini menggunakan uji One Sample KolmogorovSmirnov Test dengan taraf signifikan 0,05. Suatu data dikatakan terdistribusi secara normal apabila nilai Aximp. Sig (2-tailed) nya > dari 0,05 level of significant $(\alpha)$.

a) Skor pelayanan (Y) dengan uji One Sample Kolmogorov-Smirnov Test diperoleh nilai Aximp. Sig (2-tailed) 0,133 dengan p > 0,05 artinya nilai tersebut $>0,05$ maka variable kebahagiaan (X1) normal dan memenuhi persyaratan uji

normalitas dan sampel penelitian dapat mewakili populasi.

b) Skor kebahagiaan (X1) dengan uji One Sample Kolmogorov-Smirnov Test diperoleh nilai Aximp. Sig (2-tailed) 0,411 dengan $\mathrm{p}>0,05$ artinya nilai tersebut $>0,05$ maka variable budaya organisasi (X2) normal dan memenuhi persyaratan uji normalitas dan sampel penelitian dapat mewakili populasi.

c) Skor budaya organisasi (X2) dengan uji One Sample Kolmogorov-Smirnov Test diperoleh nilai Aximp. Sig (2-tailed) 0,766 dengan $\mathrm{p}>0,05$ artinya nilai tersebut $>0,05$ maka variable pelayanan perawat $(\mathrm{Y})$ normal dan memenuhi persyaratan uji normalitas dan sampel penelitian dapat mewakili populasi.

\section{Uji Regresi Linier Berganda}

Adapun tujuan dari penelitian ini adalah untuk menguji pengaruh kebahagiaan (X1) dan budaya organisasi (X2) terhadap pelayanan perawat. Pengujian dilakukan dengan teknik analisis regresi linier berganda. Hasil pengujian menunjukkan bahwa ada 8 pengaruh kebahagiaan (X1) dan budaya organisasi (X2) terhadap pelayanan perawat (Y). Pada ANOVA, nilai 28.526 dengan $(\mathrm{p}=0,000)$ dikarenakan $\mathrm{p}<0,05$, maka terdapat pengaruh kebahagiaan (X1) dan budaya organisasi (X2) terhadap pelayanan perawat (Y). Artinya ada pengaruh sangat signifikan antara kebahagiaan dan budaya organisasi pada pelayanan perawat. Semakin tinggi kebahagiaan dan budaya organisasi maka pelayanan perawat akan semakin baik.

\section{PEMBAHASAN}

Berdasarkan hasil pengujian menunjukkan ada pengaruh signifikan antara Kebahagiaan (X1) dan Budaya Organisasi (X2) terhadap Pelayanan Perawat (Y) di RSUD A.M. Parikesit Tenggarong nilai $\mathrm{p}<0,05$ dan nilai $\mathrm{p}$ adalah 0,000 . Sedangkan $\mathrm{R}$ Square adalah 0,426. Dalam hal ini berarti 42,6\% pelayanan perawat dipengaruhi oleh kebahagiaan dan budaya organisasi. Dengan adanya nilai yang signifikan antar variabel menunjukkan bahwa kebahagiaan dan budaya organisasi dapat mempengaruhi pelayanan perawat.

Hasil penelitian ini sejalan dengan penelitian yang dilakukan oleh Efilani (2014) hasil olah data, diketahui variabel motivasi berpengaruh signifikan terhadap variabel kinerja perawat. Hal ini didukung dengan terdapat di item-item kuesioner, yaitu penghargaan, lingkungan kerja, gaji dan pergaulan antar sesama pegawai. Hasil penelitian ini sama dengan penelitian sebelumnya, yang diteliti oleh Buheli (2012) dengan judul Faktor Yang Mempengaruhi Kinerja Perawat Dalam Penerapan Proses Keperawatan Di RSUD Toto Kabupaten Bone Bolango, menyebutkan bahwa tenaga perawat yang mempunyai motivasi tinggi, karena perawat merasa kebutuhannya sudah terpenuhi sehingga terdorong untuk lebih giat melaksanakan tugasnya. Motivasi berkaitan erat dengan dorongan yang kuat untuk melakukan setiap pekerjaan dengan hasil yang baik. 9

Hal ini sejalan juga dengan penelitian yang dilakukan oleh Kim (2014) pada 
penelitian ini diketahui ada pengaruh kebahagiaan dan budaya organisasi pada niat perawat untuk bekerja dengan baik dengan menggunakan metode t-test ANOVA, koefesien korelasi Pearson dan regresi ganda bertahap dengan nilai pergantian niat korelasi negatif yang signifikan untuk budaya organisasi afiliatif berorientasi Ada korelasi positif yang signifikan untuk kebahagiaan dan budaya organisasi terhadap niat antar perawat dalam bekerja untuk memberikan pelayanan yang baik kepada pasien.

Kebahagiaan dan budaya organisasi merupakan dua hal yang dapat mempengaruhi pelayanan perawat. Konsep pelayanan perawat sebagai suatu pelayanan yang diberikan kepada masyarakat (pelayanan publik) dan mutu pelayanan kesehatan adalah penampilan yang pantas atau sesuai (yang berhubungan dengan standar-standar) dan suatu intervensi yang diketahui aman, yang dapat memberikan hasil kepada masyarakat yang bersangkutan serta telah mempunyai kemampuan untuk menghasilkan kepuasan bagi masyarakat dalam hal kesehatan.

\section{KESIMPULAN}

Hasil penelitian menunjukkan adanya pengaruh kebahagiaan (X1) dan budaya organisasi (X2) terhadap pelayanan perawat. Hal ini tampak pada hasil pengujian hipotesis dengan nilai probabilitas $\mathrm{p}=0,000 \quad(\mathrm{p}<0,05)$ maka terdapat pengaruh kebahagiaan (X1) dan budaya organisasi (X2) terhadap pelayanan perawat (Y) dengan nilai $\mathrm{R}$ Square 0,426. Artinya ada sumbangan efektif kebahagiaan dan budaya organisasi sebesar $42,6 \%$ terhadap pelayanan perawat. Jadi dapat disimpulkan semakin tinggi kebahagiaan dan budaya organisasi maka pelayanan perawat akan semakin baik.

\section{DAFTAR PUSTAKA}

Anggraeni, Jannah . Hubungan Antara Psychological Well - Being dan Kepribadian Hardiness Dengan Stres
Pada Petugas Port Security.Program Studi Psikologi, FIP, UNESA

Azwar Asrul. 1996. Menjaga Mutu Pelayanan Kesehatan, Jakarta: Pustaka Sinar Harapan.

Buheli, Kartin. 2012. "Faktor Yang Mempengaruhi Kinerja Perawat Dalam Penerapan Proses Keperawatan Di RSUD Toto Kabupaten Bone Bolango". Ejurnal.ung.ac.id, Vol. 05, No. 01, p. 1-6

Carr, Alan. 2004. Positive Psychology: The Science of Happiness and Human

Cross, R. 1996. Midwives and Management. Hale, Cheshire: Books for Midwives Press.

Endah Purnasari. 2010. Faktor Yang Mempengaruhi Mutu Pelayanan Kebidanan. Data International Medical Travel Journal 2008

Efliani. 2014. Pengaruh Motivasi, Budaya Organisasi Dan Komitmen Organisasional Terhadap Kinerja Perawat Di Rsud Dr. Moewardi Surakarta. Universitas Muhammadiyah Surakarta

Gunarsa, S. 2012. Psikologi Perawatan. Jakarta: PT. BPK Gunung Mulia.

Gunawan, W. 2013. Analisis Pengaruh Kualitas Pelayanan Medis Dan Pelayanan Administrasi Terhadap Loyalitas Pasien (Studi Pada Pasien Rawat Inap Rumah Sakit Pertamina Cirebon). Strata Satu. Universitas Diponegoro Semarang.

Griffin Moorhead. 2013. Perilaku Organisasi. Jakarta: Salemba Empat 
Hadjam, 2001. Efektivitas Pelayanan Prima Sebagai Upaya Meningkatkan Pelayanan Di Rumah Sakit (Perspektif Psikologi). Jurnal Psikologi.

Kristianto. (2012). Mutu Rumah Sakit dapat Mencegah Malpraktik Terjadi di Rumah Sakit KOMPASIANA.

Massofa. 2008. Faktor- Faktor Yang Mempengaruhi Perilaku Dalam Berkomunikasi, Tersedia Muninjaya, I Gede, 2003. Manajemen Kesehatan, EGC: Jakarta.

Muninjaya. 2014. Manajemen Kesehatan.Jakarta : Penerbit Buku Kedokteran EGC

Munawaroh. 2000. Empati dan Intensi Prososial Pada Perawat. Skripsi Yogyakarta: Fakultas Psikologi UGM

Mulyono M.H, Hamzah, A.Z Abdullah. 2013. Faktor Yang Berpengaruh Terhadap Kinerja Perawat Di Rumah Sakit Tingkat Iii 16.06.01 Ambon. Universitas Hasanudin

Mujianto, H. 2010. Peningkatan Kinerja Pelayanan Publik Pada Balai Latihan Kerja Dengan Metode Tqm (Total Quality Management) Melalui Iso 9001:2008. Pasca Sarjana. Universitas Indonesia.

Muninjaya, I. 2004. Manajemen Kesehatan. Jakarta: EGC, pp.220-232.

Megawati, Hariyanto, T. \& Rachmi, A. 2016. Hubungan Dimensi Mutu Pelayanan Farmasi Rawat Jalan dengan Kepuasan Pasien di RS Baptis Batu: Peran Kepesertaan Asuransi.

Mongkaren, S. 2013. Fasilitas dan Kualitas Pelayanan Pengaruhnya Terhadap Kepuasan Penguna Jasa Rumah Sakit
Advent Manado. Managemen, 1(4), pp.493-503

McKenna, E., Beech, N. \& McKenna, E. 2002. Human resource management. Harlow: Financial Times Prentice Hall.

Myers G, David. 2012. Psikologi Sosial.

Jakarta:Penerbit Salemba Humanika.

Nam Kim. 2014. The Effect Nursing Organizational Culture and Happiness Index on Turnover Intention among Nurses Department of Nursing, Busan women's

Nurfaizah Darajat, Rosyidah . 2012. Hubungan Budaya Organisasi Dengan Komitmen Organisasi Perawat Bagian Rawat Inap Kelas II dan III Rumah Sakit Pku Muhammadiyah Yogyakarta. Universitas Ahmad Dahlan, Yogyakarta

Notoadmojo, S. 2007. Promosi Kesehatan dan Ilmu Perilaku. Jakarta : Rineka Cipta

Robbins, S. P.1993. Organizational Behavior: Concepts, Controversies, and Applications. Sixth Edition. Prentice Hall, Englewood Cliffs, New Jersey.

Sugiarto, E. 1999. Psikologi Pelayanan Dalam Industri Jasa. Jakarta: Gramedia Pustaka Utama.

Sugiono, 2011. Metode Penelitian Kombinasi (Mixed Methods). Bandung : ALFABETA

Setyaningsih, I. 2013. Analisis Kualitas Pelayanan Rumah Sakit Terhadap Pasien Menggunakan Pendekatan Lean ServPerf (Lean Service dan Service Performance). Jurnal Spektrum Industri. 
Seligman, M. 2002. Authentic Happiness: Using The New Positive Psychology to Realize Your Potential for Lasting Fulfi llment. New York: Free Press.

Seligman, M. 2005. Authentic Happiness: Using The New Positive Psychology to Realize Your Potential for Lasting Fulfi llment (Eva Yulia Nukman, Penerjemah). Bandung: PT. Mizan Pustaka.

Schein, E.H. 2002. Organizatiomal Culture and Leadership San Francisco : Jossey Bas Publisher,Inc

Trisantoro,2005. Good Governance dan Sistem Menjaga Mutu Pelayanan Kesehatan, Surabaya.

Tjiptono, F. 2002. Strategi Pemasaran. Yogyakarta: Andi Publisher.

Trisnantoro, L. 2005. Aspek Strategis Manajemen Rumah Sakit. Jakarta: Andi Publisher.
Uripni, C., Sujianto, U. dan Indrawati, T .2003. Komunikasi Kebidanan. EGC 2003.

Wijono, Djoko. 2015. Manajemen Mutu Pelayanan Kesehata Teori Strategi dan Aplikasi. Jakarta: Airlangga University Press.

Wheelen, Hunger. 1986. Organizational Behavior and Change.

Wood, J.M., Wallace, Zeffane, Schermerhorn, Hunt, Osborn, 2001. Organizational Behaviour an Asia-Pacific Perspective. John Wiley \& Sons, Singapore.

Yulianti. 2012. Pengaruh Perilaku Caring Perawat Terhadap Pelayanan di Ruang Rawat Inap Umum RS Dr. H. Mazoeki Mahdi Bogor. Bogor. 